\title{
Vasodilatation with captopril and prazosin in chronic heart failure: double blind study at rest and on exercise
}

\author{
JOHN BAYLISS, ${ }^{\dagger}$ RUDOLPH CANEPA-ANSON, $†$ MICHAEL S NORELL, * \\ PHILIP POOLE-WILSON, $\dagger$ GEORGE SUTTON* \\ From ${ }^{\star}$ Hillingdon Hospital, Uxbridge, Middlesex, and the $\uparrow$ National Heart Hospital and Cardiothoracic \\ Institute, London
}

SUMMARY A double blind cross over study was performed to compare the long term hormonal, haemodynamic, and clinical responses to specific inhibition of the renin-angiotensin-aldosterone system (captopril) and of the $\alpha_{1}$ adrenoceptors of the sympathetic system (prazosin) both at rest and during upright exercise in patients with chronic heart failure. Sixteen patients completed one month's treatment with each drug.

During conventional diuretic treatment (control) plasma renin activity, aldosterone, and noradrenaline were increased at rest and on exercise. Control left ventricular filling pressures were raised, and correlated significantly with plasma renin activity both at rest and on exercise. Systemic vascular resistance was increased at rest, and its reduction during exercise correlated inversely with the increase in plasma renin activity and plasma noradrenaline.

After one month's treatment with captopril there were reductions in plasma aldosterone, weight, left ventricular filling pressure, and systemic vascular resistance at rest and on exercise. Dyspnoea was relieved and exercise capacity increased. The greater fall in systemic vascular resistance on exercise no longer correlated with the increase in plasma renin activity. During treatment with prazosin there were increases in plasma noradrenaline and, transiently, in plasma aldosterone. Fluid retention occurred, and left ventricular filling pressure was unchanged. Compared with control values systemic vascular resistance was reduced at rest but not on exercise. Dyspnoea and exercise capacity did not improve.

In chronic heart failure, vasodilatation by inhibition of the $\alpha$ adrenergic system with prazosin causes compensatory stimulation of the renin-angiotensin-aldosterone system and does not result in clinical benefit. Inhibition of the renin-angiotensin-aldosterone system with captopril causes secondary vasodilatation at rest and on exercise and results in improvement in symptoms and exercise capacity.

The haemodynamic abnormalities that occur at rest and during exercise in chronic heart failure have been well documented ${ }^{12}$ At rest ventricular filling pressures are usually raised, cardiac output is

Requests for reprints to Dr G C Sutton, Hillingdon Hospital, Uxbridge, Middlesex UB8 3NN.

Present addresses: J B: Westminster Hospital, London SW1P 2AP; M S N: London Chest Hospital, London E2 9JX; R C-A: St Michael's Hospital, Toronto, Ontario, Canada.

Accepted for publication 4 November 1985 reduced, and there is arteriolar and venous constriction with abnormal distribution of blood flow. These abnormalities are accentuated during exercise and this results in breathlessness and fatigue. Treatment with directly acting vasodilating drugs usually produces acute haemodynamic changes, but the long term clinical response is often disappointing.

In chronic heart failure the sympathetic and renin-angiotensin-aldosterone systems are activated, ${ }^{34}$ and this leads to vasoconstriction and fluid retention. Some studies have investigated the 
importance of these neuroendocrine systems in heart failure in animals ${ }^{5}$ and $\operatorname{man}^{6-8}$ at rest, but there has been no controlled study of relations between hormonal changes, haemodynamic measurements, and clinical features on exercise during long term treatment of heart failure.

A double blind, randomised crossover trial was undertaken to compare the long term hormonal, haemodynamic, and clinical responses to specific inhibition of the renin-angiotensin-aldosterone system (with captopril) and of the $\alpha_{1}$ adrenoceptors of the sympathetic system (with prazosin) both at rest and during upright exercise in patients with chronic heart failure. The results of changes occurring at rest in this study have been reported elsewhere. ${ }^{9}$

\section{Patients and methods}

We studied 16 patients $(15 \mathrm{men}$ ) (mean age 62 years, range 48 to 74 years). All patients had been in heart failure for at least 3 months. The aetiology of heart failure was coronary artery disease without recent myocardial infarction in 10 patients and dilated cardiomyopathy in six. No patient had important valvar, hypertensive, or renal disease.

All patients were breathless on moderate exertion (New York Heart Association class II-III), with radiologically confirmed pulmonary venous hypertension and cardiomegaly (cardiothoracic ratio $>0 \cdot 5)$, despite optimal diuretic treatment. Frusemide (mean daily dose $138 \mathrm{mg}$ ) was given in combination with amiloride $(9 \mathrm{mg})$. Only the three patients in atrial fibrillation received digoxin for control of ventricular rate. Other vasodilating drugs and spironolactone were not used during the study. All patients gave written informed consent. The study was approved by the hospitals' ethical committees.

\section{STUDY DESIGN}

Patients were observed during a one week control period, while they were on diuretics and placebo, to ensure that they were in a stable clinical state with constant body weight and without peripheral oedema.

Control haemodynamic and hormonal measurements were then made at rest and during treadmill exercise (see below). Patients were then randomly allocated to treatment and were started on captopril (25 mg eight hourly) or prazosin ( $2 \mathrm{mg}$ eight hourly). These drugs were given double blind by the double dummy technique and the doses were doubled after one week. The doses chosen have been shown ${ }^{7}$ to produce similar acute haemodynamic effects, and are often used in clinical practice.

After one month, clinical, haemodynamic, and hormonal measurements were repeated at rest and on exercise at least two hours after the morning medication. Each patient was then crossed over, without a washout period, to receive a month of treatment with the other drug, and measurements were repeated at the end of the second month.

The initial control dose of diuretics was maintained throughout the study, unless peripheral oedema developed with a weight gain of $2.5 \mathrm{~kg}$ or more, in which case the dose of frusemide was increased for the remainder of that month of treatment.

\section{CLINICAL ASSESSMENT}

Clinical features, including nude weight, were assessed daily during the control period, and then at one and four weeks of each treatment period. Exercise capacity was assessed on a treadmill, by means of a protocol in which low workloads were increased in six-minute stages. ${ }^{10}$ Patients performed preliminary exercise tests during the control period until they achieved consistent maximal exercise. Maximal exercise time was measured at the end of the control period and at the end of each month of active treatment.

\section{HAEMODYNAMIC MEASUREMENTS}

Patients were studied by means of standard right heart haemodynamic monitoring techniques. ${ }^{11}$ Measurements were made of pulmonary artery end diastolic and right atrial pressures with the midchest as a zero reference point. Pulmonary artery end diastolic pressure was used as an indirect measure of left ventricular filling pressure. Blood pressure was measured by sphygmomanometer $(n=12)$ or brachial artery catheter $(n=4)$. Cardiac output was measured by thermodilution and the mean of at least three readings with less than $10 \%$ variation was used. Heart rate was measured from a simultaneous electrocardiogram. Mean blood pressure, cardiac index, and systemic vascular resistance were calculated by standard formulas.

In each study control measurements to assess haemodynamic stability were made over 30 minutes with the patient resting in bed. The patient then performed a symptom limited treadmill exercise test; haemodynamic measurements were made every six minutes at the end of each stage and during the minute of maximal exercise.

At the end of each month of treatment haemodynamic measurements were repeated, at rest and during treadmill exercise, two hours after medication. 


\section{HORMONAL MEASUREMENTS}

Plasma renin activity, aldosterone, noradrenaline, and vasopressin were measured during the control haemodynamic study and during the studies at the end of each month of treatment. Samples were taken at the same time as the last resting haemodynamic measurements and at maximal exercise. Samples were also taken at rest after one week on treatment, 2 hours after a maintenance dose of that month's drug. Venous blood was taken into cooled bottles, centrifuged immediately, and the plasma was stored at $-70^{\circ} \mathrm{C}$ until assay.

Plasma renin activity and aldosterone were measured by radioimmunoassay ${ }^{1213}$ (normal ranges $0.5-2.5 \mathrm{ng} / \mathrm{ml} / \mathrm{h}(0.39-1.9 \mathrm{nmol} / \mathrm{l} / \mathrm{h})$ and $100-600$ $\mathrm{pmol} / \mathrm{l}$, respectively). We measured plasma noradrenaline by radioenzymatic assay using a modification ( $P$ Sever, personal communication) of Henry's method ${ }^{14}$ (normal range 200-800 pg/ml $(1 \cdot 2-4 \cdot 7 \mathrm{nmol} / \mathrm{l}))$. Plasma vasopressin was measured by radioimmunoassay ${ }^{15}$ (normal range: 0.4-1.6 $\mu$ units/ml (0.92-3.68 pmol/1)).

\section{PLASMA DRUG CONCENTRATIONS}

Plasma captopril was not measured; increasing plasma renin activity was used as an indicator of effective converting enzyme inhibition. Plasma prazosin was measured by high pressure liquid chromatography. ${ }^{16}$ Measurements were made before and two hours after a $4 \mathrm{mg}$ maintenance dose in eight patients after one month's treatment.

\section{STATISTICAL ANALYSIS}

The trial was designed to detect a change $(p<0.05)$ in resting pulmonary artery end diastolic pressure of

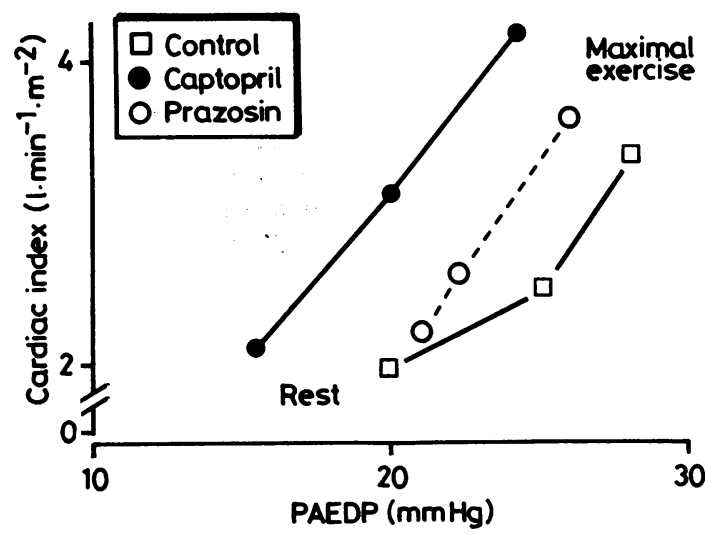

Fig. 1 Mean cardiac index and pulmonary artery end diastolic pressure (PAEDP) at rest, submaximal (6 min) and maximal exercise, in the control period, and after one month of captopril or prazosin in 16 patients. See text for statistical results, and Table I for variability.
$5 \mathrm{~mm} \mathrm{Hg}$ with a power of 0.80 . The sample size required was calculated from data previously obtained in similar patients. Statistical analysis was by analysis of variance, Student's $t$ tests for paired or unpaired data, as appropriate, and linear regression. ${ }^{1718}$ Preliminary analysis showed that order of treatment did not influence the changes in any variable ${ }^{18}$; results for the two treatment periods for each drug have therefore been combined to give a value of overall effect of that drug.

Results are given as the mean and $95 \%$ confidence limits. Hormonal values were only distributed normally after logarithmic transformation so geometric means are given for these results.

\section{Results}

There were no significant changes in any variable during the placebo period or during the control periods before each haemodynamic study.

\section{CLINICAL EFFECTS}

While on captopril 15 patients improved symptomatically, reporting a reduction in breathlessness and an increase in exercise capacity and general wellbeing; one patient did not improve. Mean weight fell by $1.6 \mathrm{~kg}(-3.2,-0.1 \mathrm{p}=0.05)$ after one month, without any increase in diuretic dosage.

On prazosin five patients reported an initial improvement in symptoms, three were unchanged, and eight deteriorated. Peripheral oedema developed in six patients. During the month of treatment mean weight increased by $2.6 \mathrm{~kg}(+0.4,+4.9$ $p=0.03$ ) despite an increase in the frusemide dosage in four patients who developed oedema after one week. Mean weight increased by $1.9 \mathrm{~kg}(+0.7$, $+3 \cdot 1, p=0.04)$ even in the 10 patients who did not become oedematous.

Mean treadmill exercise time at the end of the placebo period was $17.5 \mathrm{~min}(12.0,23.0)$; exercise was terminated by breathlessness in 11 patients, and by fatigue in five. Captopril increased exercise time by $6.2 \mathrm{~min}(+3.0,+9.5 \mathrm{p}=0.001)$; four patients who had been limited by breathlessness were now limited by fatigue. Prazosin had no effect on exercise time $(+0.7 \mathrm{~min},-5.7,+7.0 \mathrm{p}=0.81)$; eight patients were limited by breathlessness and eight by fatigue.

\section{HAEMODYNAMIC EFFECTS}

The mean control pulmonary artery end diastolic pressure was $20 \mathrm{~mm} \mathrm{Hg}$ at rest and increased to 28 $\mathrm{mm} \mathrm{Hg}$ during exercise $(\mathrm{p}=0.0006)$ (Fig. 1, Table 1). After one month of prazosin this pressure was not significantly reduced either at rest or on exercise. After captopril, pulmonary artery end diastolic pres- 
Table 1 Haemodynamic results (mean (95\% confidence limits)) at rest, submaximal and maximal exercise, in the control period, and after one month of captopril and prazosin in 16 patients. See text for statistical results

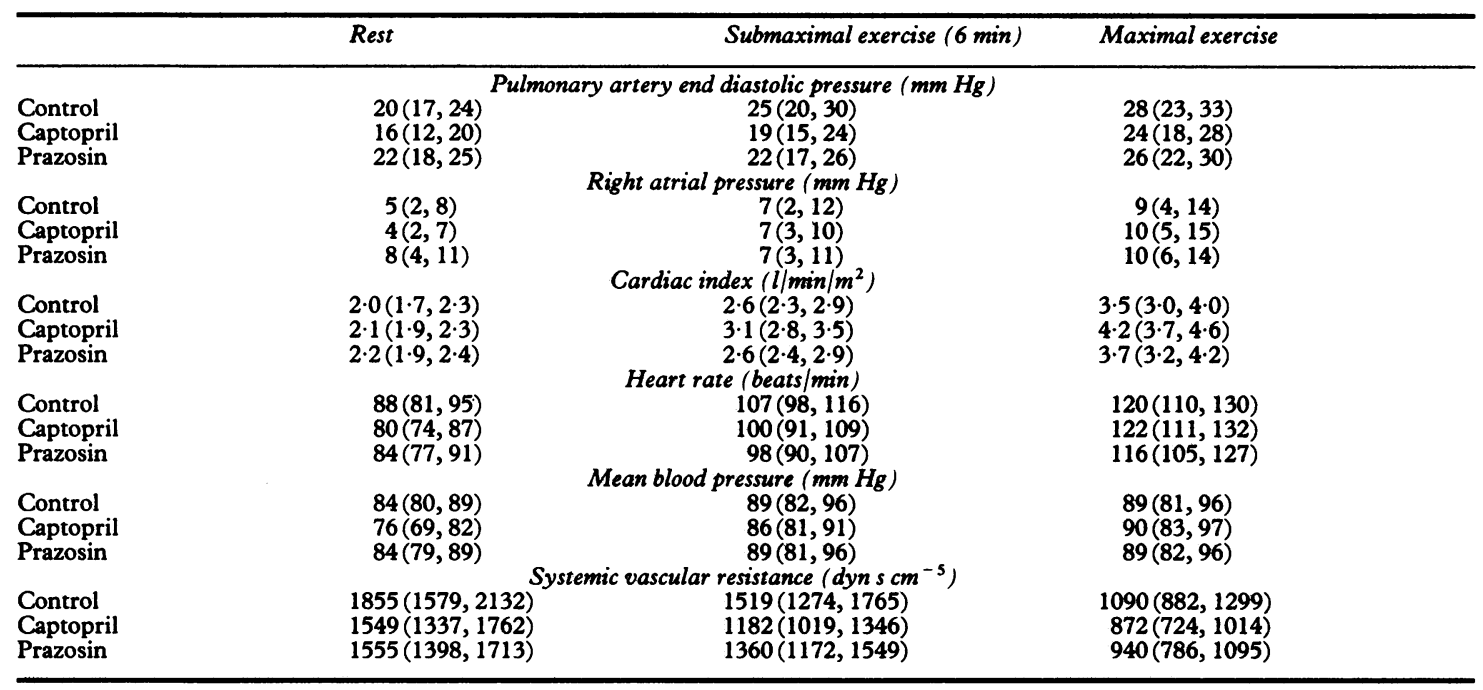

sure was reduced both at rest and during exercise $(p=0.01, p=0.05)$, despite the greater exercise workload achieved. Right atrial pressure increased during the control exercise $(p=0.009)$; neither captopril nor prazosin altered right atrial pressure significantly.

The mean control cardiac index was $2.01 / \mathrm{min} / \mathrm{m}^{2}$ at rest, and this increased to only $3.51 / \mathrm{min} / \mathrm{m}^{2}$ with maximal exercise (Fig. 1). Prazosin caused no long term change in cardiac index, either at rest or on exercise. Captopril failed to increase resting cardiac

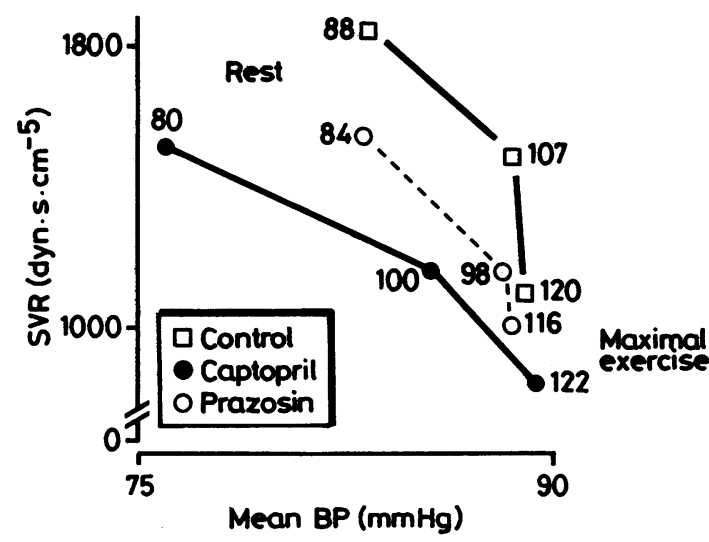

Fig. 2 Mean blood pressure (BP) and total systemic vascular resistance (SVR) at rest, submaximal $(6 \mathrm{~min})$ and maximal exercise, in the control period, and after one month of captopril and prazosin in 16 patients. Mean heart rate is shown alongside each point. See text for statistical results, and Table I for variability. index because, although it increased resting stroke $\stackrel{\odot}{\circ}$ volume index from a control value of $23 \mathrm{ml}(20,26)$ to $27(23,30 \mathrm{p}=0.01)$, it also reduced resting heart rate from 88 beats $/ \min (81,95)$ to 80 beats $/ \min (74$, $87 \mathrm{p}=0.03$ ). During exercise on captopril, cardiac index was greater than the corresponding control values, both after six minutes (submaximal exercise, $p=0.01)$ and at maximal exercise $(p=0.04)$, because of a greater increase in stroke volume. Ventricular performance therefore improved at rest and on exercise with captopril but not with prazosin (Fig. 1).

The control mean blood pressure was normal at rest, and did not change significantly on exercise $(p=0.13)$ (Fig. 2). Prazosin caused no long term change in blood pressure, either at rest or on exercise. Captopril reduced mean blood pressure at rest $(p=0.01)$ but not during exercise.

The mean control systemic vascular resistance was raised at rest, and, although it fell during exer- $D$ cise $(p<0.0001)$, it remained abnormally raised at maximal exercise (Fig. 2), suggesting that vaso- N dilatation during exercise was impaired. Arteriolar vasodilatation was maintained by both captopril and prazosin, with long term reduction in resting systemic vascular resistance $(p=0.016, p=0.04)$. During submaximal and maximal exercise on prazosin, $\stackrel{\bullet}{\subset}$ vascular resistance was not significantly different from control $(p=0.24, p=0.21)$. During exercise on captopril, vascular resistance was lower than the corresponding control values, both at submaximal $(p<0.0001)$ and maximal exercise $(p=0.04)$.

Exercise time did not correlate with pulmonary $\stackrel{\square}{\circ}$ artery end diastolic pressure at maximal exercise in 


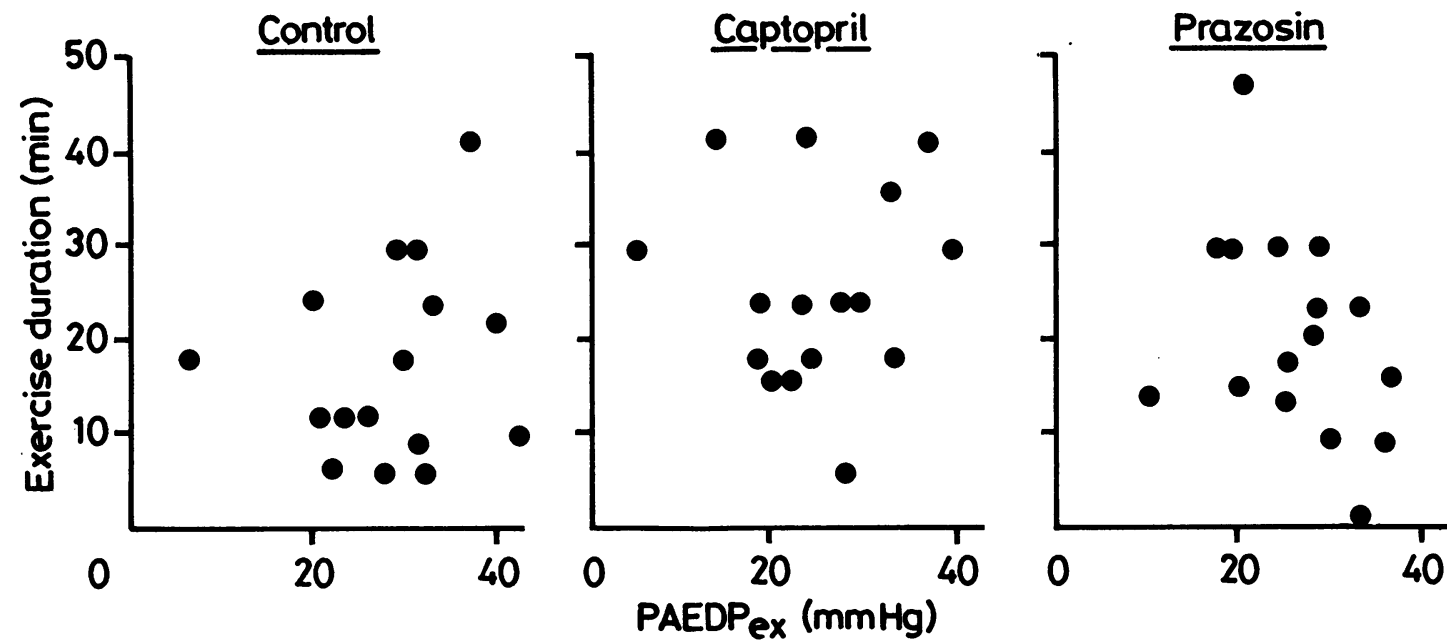

Fig. 3 Lack of relation between mean pulmonary artery end diastolic pressure at maximal exercise $\left(P A E D P_{\text {ex }}\right)$ and exercise time in the control, captopril, and prazosin periods.

the control or treatment periods $(r<0.37)$ (Fig. 3), nor did changes in exercise time with treatment correlate with changes in pulmonary artery end diastolic pressure (Fig. 4). The change in systemic vascular resistance at maximal exercise from the. control to the captopril period (representing improved vasodilatation), however, correlated inversely with the corresponding change in exercise time $(r=-0.61, p=0.011)$ - the greater the reduc-

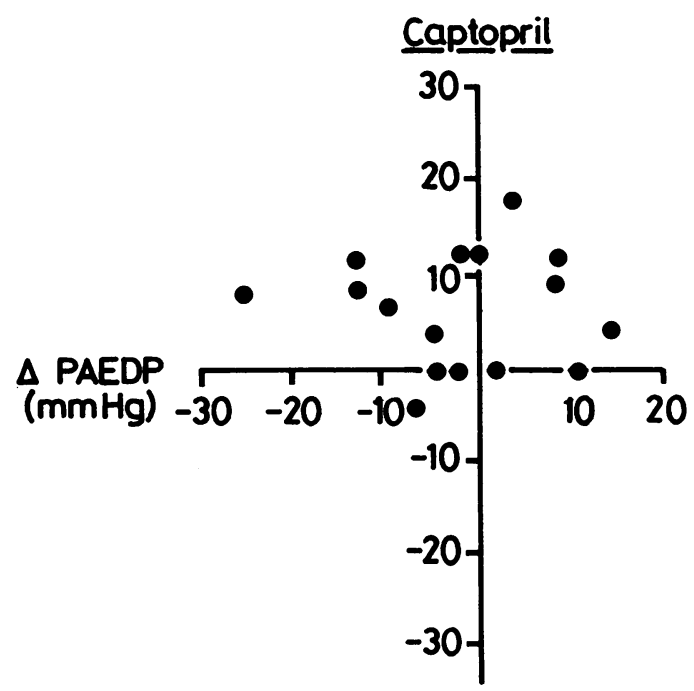

$\Delta$ Exercise duration $(\mathrm{mm})$ tion in vascular resistance on exercise the greater the increase in exercise time. This relation was not seen during exercise in patients on prazosin $(p=0 \cdot 13)$.

\section{HORMONAL EFFECTS}

The mean control plasma sodium was $136 \mathrm{mmol} / 1$ $(134,138)$, and did not change during the study. The mean control urinary sodium excretion was 120 $\mathrm{mmol} / 24 \mathrm{~h}(86,154)$; repeat measurements after one

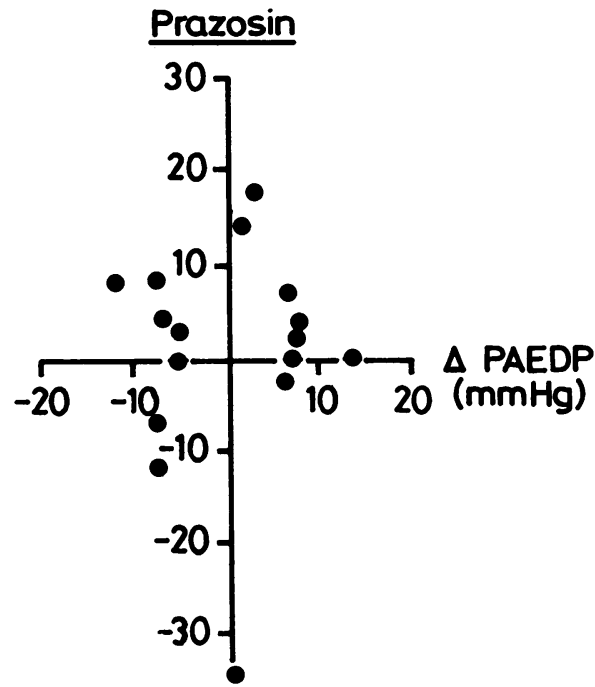

\section{$\Delta$ Exercise duration (mm)}

Fig. 4 Lack of relation between the change of mean end diastolic pressure at maximal exercise (PAEDP) and the change of exercise time with either captopril or prazosin. 
270

month of each treatment were similar, indicating a stable sodium diet.

\section{RENIN-ANGIOTENSIN-ALDOSTERONE}

SYS.TEM

Control resting plasma renin activity and aldosterone were normal in four patients, but were raised in the remaining 12 (Table 2), correlating with resting pulmonary artery end diastolic pressure $(\mathrm{r}=0.58, \mathrm{p}=0.02$ and $\mathrm{r}=0.51, \mathrm{p}=0.04$ respectively) and with resting right atrial pressure $(r=0.53$, $p=0.04$ and $r=0.77, p=0.001$ ), but not with other resting variables $(p>0 \cdot 24)$.

During exercise, there were pronounced increases in plasma renin activity and aldosterone $(p=0.0002$, $\mathrm{p}<0.0001$ ). Plasma renin activity at maximal exercise correlated with pulmonary artery end diastolic pressure and right atrial pressure at maximal exercise $(r=0.61, p=0.01$ and $r=0.51, p=0.05)$.

Inhibition of angiotensin converting enzyme with captopril increased plasma renin activity at rest and on exercise $(p=0.0006, p=0.02)$, and reduced plasma aldosterone both at rest and on exercise $(p=0.02, p=0.04)$. During captopril treatment, ventricular filling pressures were unrelated to plasma renin activity or aldosterone.

Inhibition of the $\alpha$ adrenergic sympathetic system with prazosin increased resting plasma aldosterone after one week by $296 \mathrm{pmol} / 1(+150,+441$ $\mathrm{p}=0.0009$ ). After one month, however, when fluid retention and circulatory expansion had occurred, rest and exercise values of plasma renin activity and aldosterone were similar to control values, and correlated with ventricular filling pressures $(r>0.5$, $\mathrm{p}<0.04)$.

The changes in plasma aldosterone after one week's treatment with captopril and with prazosin

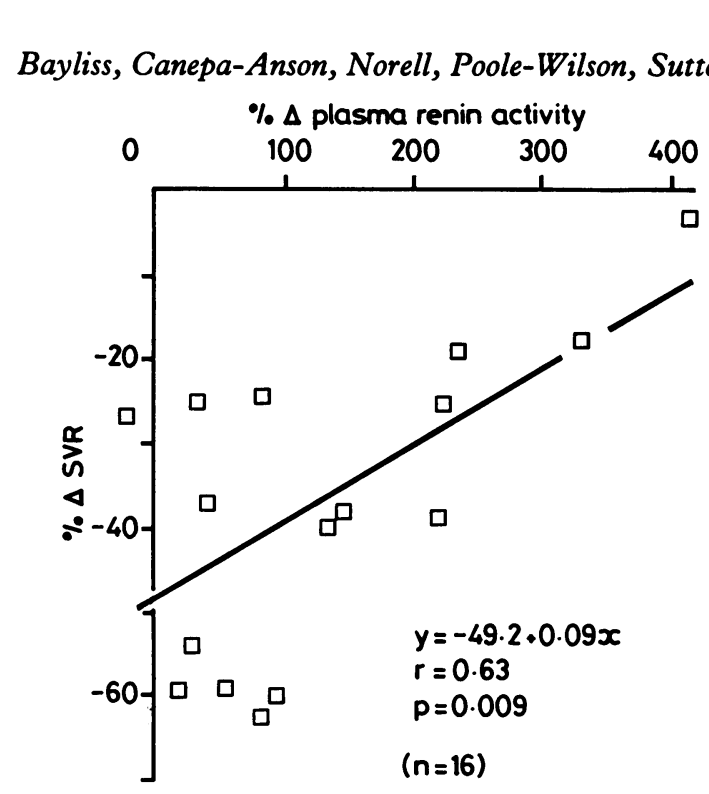

Fig. 5 Relation between percentage changes from rest to maximal exercise in plasma renin activity and systemic vascular resistance in the control period.

correlated with the changes in body weight after one month on each drug $(r=0.48, p=0.007)$.

In the control period, the exercise induced increase in plasma renin activity correlated inversely with the reduction in systemic vascular resistance on exercise ( $r=-0.63, p=0.0009)$ (Fig. 5); those patients with the greatest increase in plasma renin activity had the least vasodilatation on exercise, those with the least renin release achieved the greatest vasodilatation. This relation was no longer seen on captopril and systemic vascular resistance on exercise was lower than control values. On prazosin, the increase in plasma renin activity on exercise stil

Table 2 Hormonal values (geometric means (95\% confidence limits)) at rest and maximal exercise, in the control period, and after one month of captopril and prazosin in 16 patients. See text for statistical results

\begin{tabular}{lcc}
\hline & Rest & Maximal exercise \\
\hline & \multicolumn{1}{c}{ Plasma renin activity $(\mathbf{n g} / \mathrm{ml} / \mathbf{h})$} & $10 \cdot 3(6 \cdot 7,15 \cdot 9)$ \\
Control & $4 \cdot 9(3 \cdot 0,8 \cdot 0)$ & $22 \cdot 3(15 \cdot 8,31 \cdot 7)$ \\
Captopril & $15 \cdot 2(10 \cdot 8,21 \cdot 3)$ & $11 \cdot 1(6 \cdot 6,18 \cdot 5)$ \\
Prazosin & $5 \cdot 3(2 \cdot 9,9 \cdot 6)$ & $1189(833,1698)$ \\
& Plasma aldosterone $(\mathrm{pmol} / \mathrm{l})$ & $901(606,1340)$ \\
Control & $689(471,1007)$ & $1236(869,1758)$ \\
Captopril & $454(307,673)$ & $2252(1656,3062)$ \\
Prazosin & $544(352,839)$ & $2215(1584,3097)$ \\
Control & Plasma noradrenaline $(\mathrm{pg} / \mathrm{ml})$ & $2697(2038,3570)$ \\
Captopril & $1045(781,1398)$ & $1 \cdot 61(0 \cdot 86,3 \cdot 0)$ \\
Prazosin & $859(684,1080)$ & $1 \cdot 29(0 \cdot 74,2 \cdot 26)$ \\
Control & $1122(888,1418)$ & $1 \cdot 39(0 \cdot 79,2 \cdot 45)$
\end{tabular}

Conversion: traditional units to $S I-\mathrm{renin}: 1.0 \mathrm{ng} / \mathrm{ml} / \mathrm{h} \bumpeq 0.77 / \mathrm{mmol} / 1 / \mathrm{h} ;$ noradrenaline: $1 \mathrm{pg} / \mathrm{ml}=\bumpeq 0.0059 \mathrm{nmol} / \mathrm{l}$; vasopressin: $1 \mu$ unit $/ \mathrm{ml}=2 \cdot 3 \mathrm{pmol} / \mathrm{l}$. 
correlated inversely with the change in vascular resistance $(\mathrm{r}=-0.67, \mathrm{p}=0.002)$.

\section{PLASMA NORADRENALINE}

The control resting plasma noradrenaline was normal in five patients, but was raised in the remaining 11 (Table 2), and did not correlate with any single resting haemodynamic variable. Exercise caused a pronounced increase in plasma noradrenaline in all patients $(\mathrm{p}<0.0001)$.

On captopril, resting plasma noradrenaline was reduced $(p=0.04)$. The pattern of increase of noradrenaline during exercise on captopril was similar to that during the control period (even though a greater workload was achieved) and correlated with the exercise induced increase in heart rate $(r=0.71$, $\mathrm{p}=0.002$ ).

After one week of prazosin, resting plasma noradrenaline was increased by $371 \mathrm{pg} / \mathrm{ml}(+41,+702)$ $(2 \cdot 19 \mathrm{nmol} / \mathrm{l}:+0 \cdot 24,+4 \cdot 14)(\mathrm{p}=0.02)$, but after one month resting and exercise values were similar to control values.

During exercise in the control, captopril, and prazosin periods, the exercise induced increase in noradrenaline correlated inversely with the reduction in systemic vascular resistance on exercise $(r=-0.62$ $\mathrm{p}=0.023 ; \mathrm{r}=-0.67 \mathrm{p}=0.009 ; \mathrm{r}=-0.72 \mathrm{p}=0.003$ respectively). Those patients with the greatest increase in noradrenaline tended to have the least reduction in total systemic vascular resistance on exercise.

\section{PLASMA VASOPRESSIN}

The control resting plasma vasopressin was normal in all but three patients (Table 2), and did not correlate with plasma sodium or plasma osmolality or any haemodynamic variable. During upright exercise, plasma vasopressin increased in 12 patients $(p=0.03)$, but the peak value remained within the physiological range.

Prazosin caused no significant changes in vasopressin at rest or on exercise. During captopril treatment resting vasopressin was unchanged and there was no increase in vasopressin during exercise $(p=0.22)$ despite the greater workload achieved.

\section{PLASMA PRAZOSIN CONCENTRATIONS}

After one month's treatment, mean plasma prazosin concentration was $29.2 \mathrm{ng} / \mathrm{ml}(18,41)(0.070$ $\mathrm{mmol} / \mathrm{l}: 0.043,0.098)$ before a maintenance dose, increasing to $40.4 \mathrm{ng} / \mathrm{ml}(29,52)(0.096 \mathrm{mmol} / \mathrm{l}$ : $0.069,0.124)(t=2.87 \mathrm{p}=0.02)$ two hours after a 4 $\mathrm{mg}$ dose. These drug concentrations are high, despite the relatively low dose of prazosin used, and could have resulted in prazosin inhibiting $\alpha_{2}$ as well as $\alpha_{1}$ adrenoceptors.

\section{Discussion}

This is the first controlled study of interrelations between neuroendocrine systems, haemodynamic variables, and clinical characteristics both at rest and during upright exercise in the long term treatment of chronic heart failure.

The sympathetic and renin-angiotensin-aldosterone systems are usually activated in chronic heart failure, ${ }^{19}$ to maintain blood pressure and perfusion of the cerebral and coronary circulations. ${ }^{120}$ Renal, splanchnic, and cutaneous vasoconstriction occurs at rest and particularly during exercise, when the limited cardiac output must also supply an increased flow to working muscle. The vasodilatation that occurs in exercising muscle in healthy subjects is almost entirely due to local production of vasodilator metabolites, but in chronic heart failure this vasodilatation is impaired by mechanisms that are poorly understood. ${ }^{20}$

Homoeostatic neuroendocrine responses may have evolved to maintain the circulation during hypovolaemia and haemorrhage, ${ }^{21}$ and to some extent they may support a failing circulation in heart failure. Maintained vasoconstriction and fluid retention, however, reduce ventricular performance. ${ }^{22}$ Although directly acting vasodilating drugs can bring about short term haemodynamic improvement, long term clinical and haemodynamic benefit is often lacking, ${ }^{23}$ possibly because of further neuroendocrine activation. ${ }^{24}$

To examine the roles of the renin-angiotensinaldosterone and sympathetic systems in circulatory regulation in chronic heart failure, we performed a double blind, randomised cross over study to compare the effects of two neuroendocrine inhibitors, captopril and prazosin. ${ }^{2526}$ Captopril, an angiotensin converting enzyme inhibitor, causes vasodilatation by preventing the formation of angiotensin II, and it thus also reduces aldosterone secretion. Prazosin, an $\alpha_{1}$ adrenoceptor inhibitor, has acute vasodilator effects similar to those of captopril, ${ }^{7}$ and causes venous and arteriolar dilatation by withdrawal of sympathetic activity. We studied only stable patients with mild to moderate heart failure (New York Heart Association class II-III), to permit measurements on exercise, and because in more severely ill patients hormonal abnormalities may be less important determinants of response to treatment than the natural progression of the disease itself.

Plasma renin activity, aldosterone, and noradrenaline were raised at rest in most patients, and increased further on exercise. It has been suggested that the renin system is activated in acute phases of heart failure but then returns to normal during 
stable chronic heart failure. ${ }^{6}$ We found that the renin system was stimulated in chronic heart failure; it was not even suppressed in the patients who developed circulatory expansion on prazosin. Furthermore, patients who had near normal levels of plasma renin activity, aldosterone, or noradrenaline at rest developed greatly increased levels during exercise.

Several relations between hormonal, haemodynamic, and clinical variables were observed. Control ventricular filling pressures were raised and they correlated with plasma renin activity at rest and on exercise. Left ventricular filling pressures at maximal exercise did not correlate with exercise time, nor did any changes in filling pressures with treatment correlate with changes in exercise time. This lack of correlation between central haemodynamic variables and exercise capacity has been shown in other studies. ${ }^{27} 28$

Inhibition of the renin-angiotensin system by captopril reduced aldosterone and facilitated natriuresis, such that weight fell without an increase in diuretic dose. Left ventricular filling pressure fell both at rest and on exercise, and 15 patients reported a reduction in breathlessness. Plasma noradrenaline and heart rate were also reduced at rest on captopril, indicating some withdrawal of sympathetic activity.

Alpha adrenergic inhibition with prazosin caused vasodilatation which was associated with initial stimulation of the renin-angiotensin-aldosterone system and subsequent fluid retention, with oedema developing in six patients. Ventricular filling pressures were not reduced, and breathlessness improved in few patients.

The relation between vasopressin and ventricular filling pressures in heart failure is unclear. In the normal circulation, non-osmotic control reduces vasopressin release when atrial pressures increase, whereas in severe heart failure vasopressin release appears to occur independently of osmotic or nonosmotic control. ${ }^{29}$ The patients in this study, with moderate heart failure, may illustrate an intermediate stage in the derangement of vasopressin control, since they had normal vasopressin concentrations at rest and on exercise, but these did not respond appropriately to changes in atrial pressures.

The total systemic vascular resistance in our patients was invariably raised, reflecting vasoconstriction in at least some vascular beds. Relations between vasoconstriction and neuroendocrine systems were studied by assessing the effects of exercise, before and in the presence of captopril and prazosin.

During the control period the reduction in systemic vascular resistance during exercise correlated inversely with increases in plasma renin activity and noradrenaline, suggesting that both angiotensin II and adrenergic mechanisms were limiting vasodilatation. Inhibition of $\alpha_{1}$ adrenoceptors with prazosin resulted in arteriolar vasodilatation at rest; during exercise it might have been expected that prazosin would facilitate vasodilatation by blocking $\alpha$ adrenoceptors and allowing unopposed stimulation of vasodilating $\beta_{2}$ receptors. The reduction in vascular resistance during exercise, however, was no greater than in the control period; it still correlated inversely with renin and noradrenaline release, and exercise capacity did not increase. Exercise capacity in chronic heart failure is related to nutritive muscle blood flow during exercise, ${ }^{30}$ and is only poorly related to central haemodynamic variables. ${ }^{27} 28$ Since prazosin caused vasodilatation at rest, but did not facilitate greater vasodilatation on exercise, or increase exercise capacity, our results can be interpreted as indirect evidence that prazosin did not increase muscle blood flow.

With inhibition of the renin-angiotensin system by captopril, systemic vascular resistance was reduced from control values both at rest and on exercise, even though plasma noradrenaline still increased. The change in systemic vascular resistance on exercise was no longer correlated with the change in plasma renin activity. The improved vasodilatation on exercise was associated with an increased exercise capacity, suggesting there had been an improvement in muscle blood flow. ${ }^{30-32}$

Although hormonal and haemodynamic changes occur immediately after administration of captopril, exercise capacity does not improve immediately, but increases progressively over a period of weeks. ${ }^{33}$ Neither the acute changes in angiotensin II nor any acute haemodynamic changes can thus be directly responsible for the changes in exercise capacity. More long term changes in muscle blood flow on exercise are likely to be involved.

It has been suggested that the impairment of maximal vasodilatation in exercising muscle in heart failure is due to a "vascular stiffness factor", possibly related to the sodium content of the blood vessel wall. ${ }^{19}$ Our study provides indirect evidence that angiotensin II may be such a factor, acting directly or indirectly through its effects on aldosterone and increasing the stiffness and sodium content of the vessel wall.

This study has established the important contribution of neuroendocrine systems in determining the haemodynamic and clinical features of chronic heart failure at rest and during exercise, and illustrates how inhibition of the renin-angiotensinaldosterone system, in particular, can result in long term clinical improvement.

We thank Dr G A MacGregor (Charing Cross Hos- 
pital, London) for plasma renin activity and aldosterone assays, Prof P Sever (St Mary's Hospital Medical School, London) for noradrenaline assays, and Dr Mary Forsling (Middlesex Hospital Medical School, London) for vasopressin assays. Plasma prazosin was measured by D Stevenson (University of Surrey), courtesy of Pfizer Ltd. Prazosin and placebo were kindly supplied by Pfizer Ltd. Captopril and placebo were kindly supplied by Squibb UK Ltd.

\section{References}

1 Wade OL, Bishop JM. Cardiac output and regional blood flow. Oxford: Blackwell Scientific, 1962: 134-48.

2 Ross J, Gault JH, Mason DT, Linhart JW, Braunwald E. Left ventricular performance during muscular exercise in patients with and without cardiac dysfunction. Circulation 1966; 34: 597-608.

3 Thomas JA, Marks BH. Plasma norepinephrine in congestive heart failure. Am f Cardiol 1978; 41: 233-43.

4 Brown JJ, Davies DL, Johnson VW, Lever AF, Robertson JIS. Renin relationships in congestive cardiac failure, treated and untreated. Am Heart $\mathcal{F}$ 1970; 80: 329-42.

5 Riegger AJG, Liebau G. The renin-angiotensin-aldosterone system, antidiuretic hormone and sympathetic nerve activity in an experimental model of congestive heart failure in the dog. Clin Sci 1982; 62: 465-9.

6 Dzau VJ, Colucci WS, Hollenberg NK, Williams GH. Relation of the renin-angiotensin-aldosterone system to clinical state in congestive heart failure. Circulation 1981; 63: 645-51.

7 Kluger J, Cody RJ, Laragh JH. The contributions of sympathetic tone and the renin-angiotensin system to severe chronic congestive heart failure: response to specific inhibitors (prazosin and captopril). $A m$ f Cardiol 1982; 49: 1667-74.

8 Nishioka A, Kubo S, Hirota Y, Kawamura K. Takatsu T. A clinical study on the role of the renin-angiotensin-aldosterone system and catecholamines in chronic congestive heart failure. Fpn Heart f 1982; 4: 527-44.

9 Bayliss J, Norell M, Canepa-Anson R, Reid C, Poole-Wilson P, Sutton G. Clinical importance of the renin-angiotensin system in chronic heart failure: double blind comparison of captopril and prazosin. $\mathrm{Br}$ Med $\mathcal{F} 1985$; 290: 1861-5.

10 Canepa-Anson R, Reid C, Gibbs S, et al. Limiting symptoms in chronic heart failure are dependent on rate of increase of workload and are independent of haemodynamics. Clin Sci 1984; 66: [Abstract] 51P.

11 Bayliss J, Norell M, Ryan A, Thurston M, Sutton GC. Bedside haemodynamic monitoring: experience in a general hospital. $\mathrm{Br}$ Med f 1983; 287: 187-90.

12 Roulston JE, MacGregor GA. Measurement of plasma renin activity by radioimmunoassay after prolonged cold storage. Clin Chim Acta 1978; 88: 45-8.

13 Jones VHT, Wilson GA. Determination of aldosterone in biological fluids. In: Reid E, ed. Assay of drugs and other trace compounds in biological fluids. Methodological development in biochemistry Vol. 5 Amersham: Elsevier, North Holland 1976; 149-58.

14 Henry DP, Starman BJ, Johnson DG. A sensitive radio- enzymatic assay for norepinephrine in tissue and plasma. Life Sci 1975; 16: 375-84.

15 Aziz LA, Forsling ML, Woolf CJ. The effect of intracerebroventricular injections of morphine on vasopressin release in the rat. $f$ Physiol (Lond) 1981; 311: 401-10.

16 Rubin PC, Brunton J, Meredith P. UK 33274 determination by HPLC using fluorescence detection. I Chromatogr 1980; 221: 193-5.

17 Altman DG, Gore SM, Gardner MJ, Pockock SJ. Statistical guidelines for contributors to medical journals. $\mathrm{Br}$ Med f 1983; 286: 1489-93.

18 Hills $\mathrm{M}$, Armitage $\mathrm{P}$. The two period cross-over trial. $\mathrm{Br} f \mathrm{Clin}$ Pharmacacol 1979; 8: 7-20.

19 Cohn JN, Levine TB, Francis GS, Goldsmith S. Neurohumoral control mechanisms in congestive heart failure. Am Heart f 1981; 102: 509-14.

20 Zelis R, Flaim SF. Alterations in vasomotor tone in congestive heart failure. Prog Cardiovasc Dis 1982; 24: 437-59.

21 Harris P. Evolution and the cardiac patient. Cardiovasc Res 1983; 17: 437-45.

22 Cohn JN. Vasodilator therapy for heart failure. The influence of impedance on left ventricular performance. Circulation 1973; 48: 5-8.

23 Walsh W, Greenberg BH. Results of long-term vasodilator therapy in patients with refractory congestive heart failure. Circulation 1981; 64: 499-505.

24 Markham RV, Gilmore A, Pettinger W, Brater DC, Corbett JR, Firth BG. Central and regional haemodynamic effects and neurohumoral consequences of minoxidil in severe congestive heart failure and comparison to hydralazine and nitroprusside. $A m \mathcal{F}$ Cardiol 1983; 52: 774-81.

25 The captopril multicentre research group. A placebo controlled trial of captopril in refractory chronic congestive heart failure. $\mathcal{F}$ Am Coll Cardiol 1983; 4: 755-63.

26 Awan NA, Mason DT. Oral vasodilator therapy with prazosin in severe congestive heart failure. Am Heart $f$ 1981; 101: 695-700.

27 Franciosa JA, Cohn JN. Immediate effects of hydralazineisosorbide dinitrate combination on exercise capacity and exercise hemodynamics in patients with left ventricular failure. Circulation 1979; 59: 1085-91.

28 Franciosa JA, Goldsmith SR, Cohn JN. Contrasting immediate and long-term effects of isosorbide dinitrate on exercise capacity in congestive heart failure. $A m \mathcal{F} M e d$ 1980; 69: 559-66.

29 Goldsmith SR, Francis GS, Cowley AW, Levine TB, Cohn JN. Increased plasma arginine vasopressin levels in patients with congestive heart failure. $7 \mathrm{Am}$ Coll Cardiol 1983; 1: 1385-90.

30 Wilson JR, Martin JL, Ferraro N. Impaired skeletal muscle nutritive flow during exercise in patients with congestive heart failure: role of cardiac pump dysfunction as determined by the effect of dobutamine. Am $\mathcal{F}$ Cardiol 1984; 53: 1308-15.

31 Mancini D, Davis L, Wexler JP, Chadwick B, LeJemtel TH. Long-term therapy with captopril improves maximal oxygen uptake by increase skeletal muscle blood flow in patients with heart failure [Abstract]. Circulation 1984; 70: II-193.

32 Cowley AJ, Rowley JM, Stainer K, Hampton JR. Effects of captopril on abnormalities of the peripheral circulation and respiratory function in patients with severe heart failure. Lancet 1984; ii: $1120-4$.

33 Cowley AJ, Rowley JM, Stainer K, Hampton JR. Captopril therapy for heart failure. A placebo controlled study. Lancet 1982; ii: $730-2$. 